\title{
Mineral Mudah Lapuk Material Piroklastik Merapi dan Potensi Keharaannya Bagi Tanaman
}

\author{
DOI 10.18196/pt.2016.060.84-94
}

\author{
Lis Noer Aini ${ }^{1 *}$, Mulyono ${ }^{1}$, Eko Hanudin ${ }^{2}$ \\ ${ }_{1}^{1}$ Program Studi Agroteknologi, Fakultas Pertanian, Universitas Muhammadiyah Yogyakarta, Jl. Lingkar Selatan, Kasihan, Bantul, Yogyakarta \\ 55183, Indonesia Telp. 0274 387656, ${ }^{2}$ Jurusan Ilmu Tanah, Fakultas Pertanian, Universitas Gadjah Mada, Jl. Flora, Bulaksumur, Depok, \\ Sleman, Yogyakarta 55281, Indonesia, Telp./fax.: (0274) 563062, \\ e-mail: nenny@umy.ac.id
}

\begin{abstract}
ABSTRAK
Erupsi Gunung Merapi memberikan dampak negatif bagi masyarakat, namun di sisi lain terdapat manfaat besar didalamnya yaitu melakukan penyuburan kembali terhadap tanah yang ada. Proses pemudaan kembali tanah dengan material yang kaya akan unsur hara sering dikenal dengan istilah rejuvinalisasi (pemudaan kembali). Secara umum, batuan mengandung mineral tertentu maupun kumpulan mineral, yang mempunyai potensi keharaan cukup besar yang dapat dimanfaatkan oleh tanaman dalam bentuk mineral mudah lapuk (weatherable minera). Oleh karena itu, informasi mengenai kandungan mineral primer material vulkanik Gunung Merapi yang memiliki potensi keharaan bagi tanaman perlu diketahui. Hasil identifikasi menunjukkan bahwa material piroklastik Merapi berasal dari magma andesit basaltik dengan kandungan mineral primer mudah lapuk dominan berupa plagioklas. Pemanfaatan material vulkanik sebagai agromineral dapat dilakukan, karena kandungan hara potensial yang ada dalam mineralnya, dan termasuk ke dalam golongan mineral yang mudah lapuk. Kata Kunci: Material Vulkanik Merapi, Weathearable Mineral, Potensi Keharaan
\end{abstract}

\begin{abstract}
The eruption of Mount Merapi had been giving adverse effect for the community, but on the other hand, there are great benefits in it such as the enrichment back to the land. Enrichment process in land with materials that are rich in nutrients is often known as rejuvenation. In general, the rocks containing certain minerals or mineral assemblages, which has large amount of the potential nutrient that can be used by plants in the form of weathered minerals. Therefore, it is a big question about the relationship between primer mineral deposits on Mount Merapi volcanic material with the potential nutrient for crop. The results showed that the identification of Merapi pyroclastic material derived from basaltic andesite magma with primary mineral content easily weathered the dominant form of plagioclase. Utilization of volcanic material as macromineral is easy to use, because the nutrient content of the existing potential in minerals included in the group of minerals that easily weathered.
\end{abstract} Keywords: Merapi volcano Material; Weathearable Mineral; Potential Nutrient

\section{PENDAHULUAN}

Indonesia terletak di dalam lingkar cincin api (Ring of Fire) Pasifik, dimana zona ini merupakan pusat sumber gempa dan tempat tumbuhnya sebagian besar gunung api di dunia. Merapi merupakan salah satu dari 129 gunung api aktif yang ada di Indonesia, dan termasuk gunung yang paling aktif dan paling muda dari deretan gunung api di Jawa dengan ancaman bahaya utama adalah aliran awan panas (pyroclastic flow). Gunung api yang secara administrasi terletak di Provinsi Jawa Tengah dan Daerah Istimewa Yogyakarta ini mempunyai tipe strato volcano dengan kandungan magma yang bersifat andesitbasaltik. Gunung ini mempunyai ketinggian
$2978 \mathrm{~m}$, diameter $28 \mathrm{~km}$, luas 300-400 km² dan volume $150 \mathrm{~km}^{3}$. Erupsi Merapi sering terjadi dengan siklus rata-rata berkisar antara 2-5 tahun (PVMBG, 2006).

Erupsi adalah peristiwa keluarnya magma di permukaan bumi. Proses keluarnya magma ini berbeda-beda untuk setiap gunung api. Secara umum, proses erupsi dapat dibedakan menjadi 2, yaitu eksplosif dan efusif. Erupsi eksplosif yaitu proses keluarnya magma dalam bentuk ledakan, biasanya akan terbentuk endapan piroklastik. Sementara erupsi efusif, yaitu proses keluarnya magma terjadi dalam bentuk aliran lava. Berdasarkan sejarah erupsi yang terjadi, 
Merapi mempunyai dua pola erupsi, yaitu: 1) efusif, yang diikuti dengan pertumbuhan kubah lava, yang selalu berulang setiap 4-6 tahun dan menghasilkan aliran piroklastik yang dikenal dengan Merapi-type nuées ardentes, 2) erupsi eksplosif dengan runtuhan dan aliran piroklastik mencapai 10-15 km dari puncak dalam (Badan Geologi Kementerian Energi dan Sumberdaya Mineral, 2014; Budi-Santoso, et al., 2013; Fiantis, et al., 2009).

Erupsi Gunung Merapi yang terjadi memberikan dampak negatif bagi masyarakat, namun pada sisi lain ada manfaat besar didalamnya yaitu melakukan penyuburan kembali terhadap tanah yang ada. Proses pemudaan kembali tanah dengan material yang kaya akan unsur hara sering dikenal dengan istilah rejuvinalisasi (pemudaan kembali). Sesaat setelah terjadinya aliran piroklastik, proses pembentukan tanah sudah dimulai melalui proses pelapukan elemen dan mineral yang terkandung di dalamnya. Di bidang pertanian, selain selalu memberikan bahan baru dalam proses pembentukan tanah, material piroklastik juga memberikan tempat tumbuh yang layak bagi tanaman dengan menyediakan nutrisi tanaman di dalam mineral yang dikandungnya (Fiantis, et.al., 2009). Secara umum, tanaman dalam hidupnya membutuhkan paling tidak 17 macam unsur hara. Sembilan unsur hara makro ada dalam jaringan tanaman dengan kadar lebih dari 0,1 \% berat kering (C, H, O, N, K, Ca, Mg, P, S) dan delapan unsur hara mikro dengan kadar kurang dari $100 \mathrm{ug} / \mathrm{g}$ berat kering (B, Cl, Cu, Fe, Mn, Mo, Ni, Zn) (Welch, 1995). Di samping hara makro dan mikro juga ada hara yang dikategorikan ke dalam hara bermanfaat (beneficial nutrients) seperti: $\mathrm{Co}, \mathrm{Na}$, dan Si. Hara essensial C, $\mathrm{H}, \mathrm{O}$ masing-masing diperoleh dari $\mathrm{CO}_{2}, \mathrm{H}_{2} \mathrm{O}$, $\mathrm{O}_{2}$ dan bahan organik. Sementara hara essensial yang lain ditemukan dalam mineral aluminosi- likat, ferromagnesian silikat dan mineral-mineral tambahan lain dalam batuan (Harley dan Gilkes, 2000). Di antara hara makro, K merupakan yang paling banyak menggunakan mineral batuan sebagai sumber pasokannya, seperti feldspar (Sanz Scovino and Rowell, 1988), lava (von Fragstein et al., 1988), granit, diorit, diabase, basalt dan abu volkanik (Blum et al., 1989a, Coroneos et al., 1996; Hinsinger et al., 1996), gneiss, syenit dan amfibol (Baerug, 1991a), granit, karnokit, dolerit dan mika pegmatitik (Niwas et al., 1987; Weerasuryia et al., 1993). Disamping itu von Fragstein et al. (1988) juga menggunakan mineral basalt, diabase, fonolit dan lava sebagai sumber $\mathrm{Ca}, \mathrm{Mg}$ dan Fe. Blum et al. (1989a) menggunakan granit, diabase, basalt dan abu volkanik sebagai sumber Ca, Mg dan P. Baerug (1991b) juga mencoba menggunakan gneiss, syenit dan amfibol sebagai sumber hara Mg. Lebih lanjut von Fragstein et al. (1988) dan Blum et al. (1989a) mengembangkan mineral batuan tersebut sebagai sumber hara mikro bagi tanaman.

Material vulkanik yang dikeluarkan oleh gunung berapi biasanya banyak mengandung mineral primer yang berpotensi sebagai sumber hara bagi tanaman. Kecepatan mineral primer ini untuk melapuk sehingga memiliki nilai keharaan bagi tanaman sangat dipengaruhi oleh komposisi kation-anion penyusunnya. Kelompok mineral mudah lapuk (weatherable primary mineral) biasanya ditandai oleh banyaknya kandungan logam alkali dan alkali tanah seperti $\mathrm{Na}, \mathrm{K}, \mathrm{Ca}$ dan Mg. Oleh karena itu perlu diketahui kandungan mineral primer Gunung Merapi setelah terjadinya erupsi tahun 2010 untuk melihat potensi keharaan yang tersedia bagi tanaman.

\section{BAHAN DAN METODE}

Penelitian dilaksanakan di lereng selatan Gunung Merapi yang merupakan daerah terdampak 
erupsi Merapi tahun 2010, pada ketinggian antara 1000 - 1200 m.dpl., pada bulan Maret-Agustus 2015. Penelitian diawali dengan pengambilan sampel pada 3 (tiga) titik yang mewakili kawasan yang terdampak erupsi Merapi, yaitu sisi sebelah timur, tengah, dan barat. Pengambilan sampel dilakukan dengan membuat mini profil (minipit) dengan kedalaman 50 - $100 \mathrm{~cm}$ pada ketiga titik sampel, kemudin diambil sampel tanah per lapisan yang terbentuk. Dari ketiga titik sampel tersebut, diperoleh 19 sampel tanah per lapisan.

Analisis mineral dilakukan menggunakan X-Ray Diffraction untuk mendapatkan kandungan mineral primer mudah lapuk yang ada pada sampel tanah. Hasil analisis mineral dianalisis secara deskriptif berdasarkan grafik yang menunjukkan kandungan mineral.

\section{HASIL DAN PEMBAHASAN}

Mineral Mudah Lapuk (Weatherable Mineral)

Mineral adalah bahan atau elemen yang terjadi secara alamiah yang mempunyai kompo- sisi kimia tertentu kombinasi dari senyawa an organik dan struktur kristal yang khas (Jessey \& Tarman, 2014; Mitchel \& Soga, 2005). Secara umum, batuan mengandung mineral tertentu maupun kumpulan mineral. Mineral mempunyai komposisi kimia tertentu dan menjadi penyusun komponen (pola kristal). Namun beberapa mineral tidak mempunyai struktur kristal (amorf). Hirarki atau tingkat kemudahan mineral untuk melapuk disajikan dalam Gambar 1 yang dikenal dengan Reaksi Bowen. Pada umumnya mineral yang mengkristal lebih cepat pada suhu yang sangat tinggi akan lebih mudah terlapukkan daripada yang mengkristalnya lebih akhir pada suhu yang lebih rendah (Goldschmidt, 1958). Komposisi kimia dari masing-masing mineral tersebut tersaji pada Tabel 1. Reaksi Bowen tersebut juga sangat berhubungan dengan stabilitas pelapukan (Tabel 2) yang menunjukkan kemampuan mineral dalam melepaskan unsur kimia dalam hal ini unsur hara yang dibutuhkan oleh tanaman (Mitchell \& Saga, 2005).

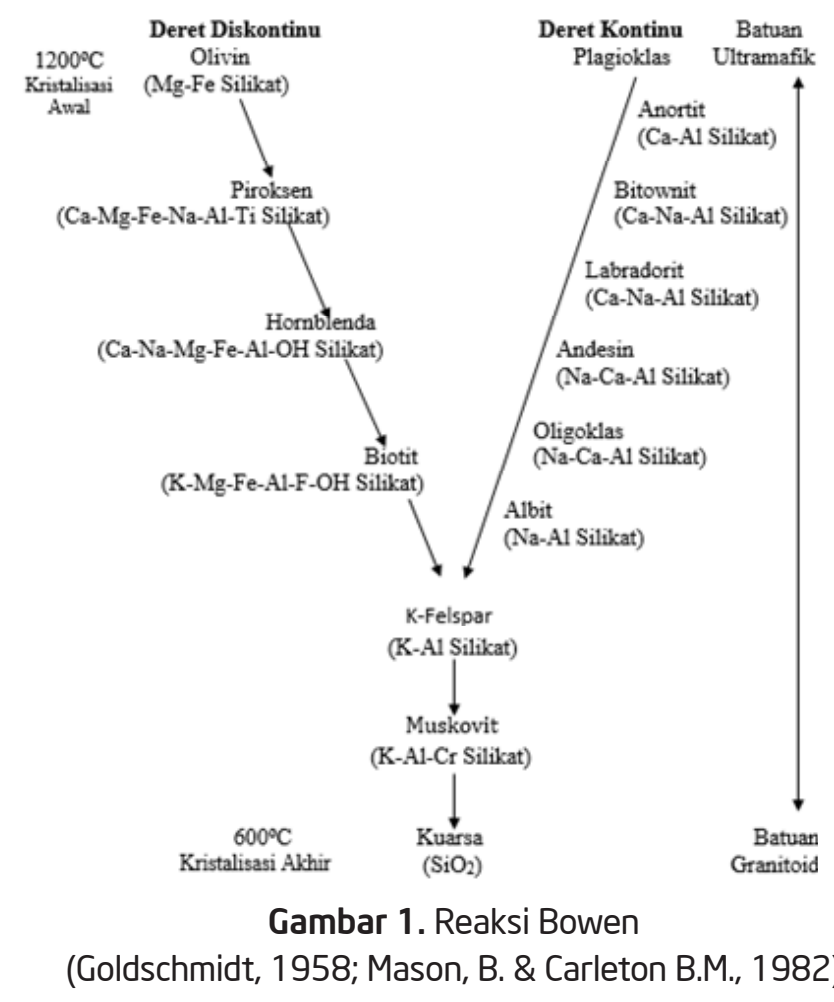


Tabel 1. Kandungan Unsur Kimia dalam Mineral

\begin{tabular}{|c|c|}
\hline Nama Mineral & Rumus Kimia \\
\hline $\begin{array}{l}\text { Quartz } \\
\text { Feldspar } \\
\text { Mica } \\
\text { Amphibole } \\
\text { Pyroxene } \\
\text { Olivine } \\
\text { Epidote } \\
\text { Tourmaline } \\
\text { Zircon } \\
\text { Rutile } \\
\text { Kaolinite } \\
\text { Smectite, vermiculite, chlorite } \\
\text { Allophane } \\
\text { Imogolite } \\
\text { Gibbsite } \\
\text { Goethite } \\
\text { Hematite } \\
\text { Ferrihydrate } \\
\text { Birnessite } \\
\text { Calcite } \\
\text { Gypsum }\end{array}$ & 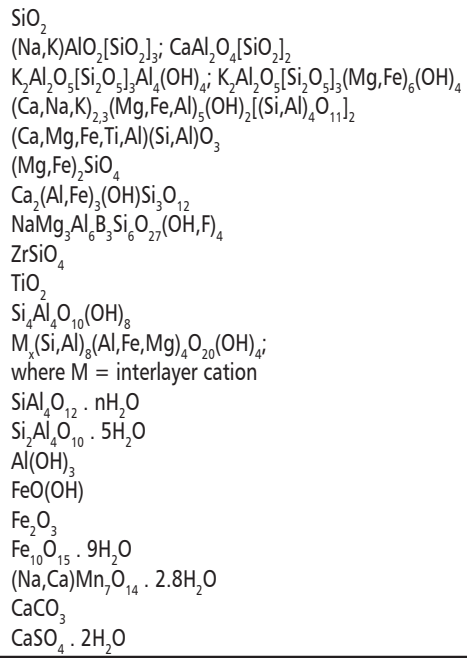 \\
\hline
\end{tabular}

Sumber: Sposito (1989) cit. Mitchell \& Saga (2005)

Tabel 2. Representatif Mineral pada Tingkat Pelapukan

\begin{tabular}{|c|c|}
\hline Tingkat Pelapukan & Representatif Mineral \\
\hline \multirow[t]{5}{*}{ Early Weathering Stage } & Gypsum (also halite, sodium nitrat) \\
\hline & Calcite (also dolomite apatite) \\
\hline & Olivine-hornblende (also pyroxenes) \\
\hline & Biotite (also glauconite, nontronite) \\
\hline & Albite (also anorthite, microcline, orthoclase) \\
\hline \multirow[t]{4}{*}{ Intermediate Weathering Stage } & Quartz \\
\hline & Muscovite (also illite) \\
\hline & $\begin{array}{l}\text { 2:1 layer silicate (including vermiculite, expanded } \\
\text { hydrous mica) }\end{array}$ \\
\hline & Montmorillonite \\
\hline \multirow[t]{4}{*}{ Advanced Weathering Stage } & Kaolinite \\
\hline & Gibbsite \\
\hline & Hematite (also goethite, limonite) \\
\hline & Anatase (also rutile, zircon) \\
\hline
\end{tabular}

Sumber: Jackson \& Sherman (1953) cit. Mitchell \& Saga (2005)

Tabel 2 menunjukkan kecepatan mineral dapat melapuk. Proses pelapukan yang terjadi dalam mineral, sangat terkait dengan stabilitas dan unsur penyusun mineral. Reaksi Bowen menggambarkan bahwa semakin rendah temperatur pembentukan mineral, maka proses kristalisasi mineral akan semakin stabil. Pada mineral dengan kristal yang semakin stabil, maka proses pelapukan yang terjadi juga akan semakin sulit.
Pada tanah-tanah yang banyak mengandung mineral yang sangat mudah lapuk (early weathering stages) menunjukkan bahwa tanah tersebut masih muda atau belum mengalami pelapukan lanjut. Semakin lanjut proses pelapukan yang terjadi, maka tanah yang ada juga akan semakin tidak subur yang ditandai dengan adanya mineral sulit terlapukkan (advanced weathering mineral).

\section{Kandungan Mineral Pada Material Vulkanik Gunung Merapi}

Kandungan mineral dalam bumi sebagian akan keluar pada saat terjadi proses erupsi gunung api. Kandungan bahan kimia pada material sangat tergantung dari sumber magma. Pada batuan volkanik, terdapat 4 tipe batuan yang didasarkan pada kandungan silika $\left(\mathrm{SiO}_{2}\right)$, yaitu: Basalt (48-52\%), Andesit (52-63\%), Dacite (63-68\%) dan Rhyolite (>68\%). Kandungan yang lain adalah titanium $\left(\mathrm{TiO}_{2}\right)$, aluminum $\left(\mathrm{Al}_{2} \mathrm{O}_{3}\right)$, besi ( $\mathrm{FeO}$ atau $\mathrm{Fe}_{2} \mathrm{O}_{3}$ ), Mangan $(\mathrm{MnO})$, Calcium $(\mathrm{CaO})$, Sodium $\left(\mathrm{Na}_{2} \mathrm{O}\right)$, Kalium $\left(\mathrm{K}_{2} \mathrm{O}\right)$ dan Phospat $\left(\mathrm{P}_{2} \mathrm{O}_{5}\right)$. Dari tipe batuan dan bahan kimia yang terkandung di dalamnya, sangat menentukan komposisi kimia dari material vulkanik yang dihasilkan pada suatu erupsi (USGS, 2014, Ivanov et al., 2014 ).

Material piroklastik Merapi pada berbagai periode erupsi mempunyai kandungan senyawa kimia yang sedikit berbeda. Analisis menggunakan X-Ray Fluorescence (XRF), pada periode erupsi tahun 1992-1993 dan 1994-1995, komposisi material kubah lava adalah $52 \% \mathrm{SiO}_{2}$, $16 \% \mathrm{Al}_{2} \mathrm{~S}_{3}, 4 \% \mathrm{MgO}, 8 \% \mathrm{CaO}, 0,3 \% \mathrm{MnO}, 7 \%$ $\mathrm{FeO}, 4 \% \mathrm{NaO}$ dan 2,4\% K2O (Hammer, et al., 2000 cit. Fiantis, et al., 2009). Sementara hasil penelitian Fiantis et al. (2009) terhadap material piroklastik Merapi tahun 2006, kandungan senyawa yang diperoleh adalah $\mathrm{SiO}_{2} 61,55 \%$, $\mathrm{Al}_{2} \mathrm{O}_{3} 15,85 \%, \mathrm{Fe}_{2} \mathrm{O}_{3} 4,90 \%, \mathrm{CaO} 5,89 \%, \mathrm{MgO}$ 
$1,43 \%, \mathrm{Na}_{2} \mathrm{O} 4,22 \%, \mathrm{~K}_{2} \mathrm{O} 2,82 \%, \mathrm{P}_{2} \mathrm{O}_{5} 0,28 \%$, $\mathrm{MnO} 0,14 \%, \mathrm{TiO}_{2}$ 0,85\%, $\mathrm{H}_{2} \mathrm{O}$ 0,38\% dan $\mathrm{H}_{2} \mathrm{O}^{+} 1,83 \%$. Pada material piroklastik sebelum erupsi tahun 2010 menunjukkan bahwa komposisinya adalah andesit-basaltik dengan kandungan mineral dominan adalah Ca-plagioklas dimana kandungan silika lebih dari 61\%.

Perbedaan kandungan material piroklasitik Merapi juga ditunjukkan dari komposisi mineral primer yang teridentifikasi. Komposisi material piroklastik erupsi tahun 2006 tersaji pada Tabel 3 (Fiantis et al., 2009). Sementara hasil sayatan tipis batuan dengan metode pengamatan secara petrografi material piroklastik hasil erupsi tahun 2010 tersaji pada Tabel 4.

Tabel 3. Komposisi Mineral Primer Material Piroklastik Erupsi Tahun 2006

\begin{tabular}{lc}
\hline Tipe Mineral & Kandungan (\%) \\
\hline Opak & 1 \\
Hornblende & Trace \\
Hypersthene & 3 \\
Augite & 2 \\
Apatite & Trace \\
Volcanic glass & 60 \\
Labradorite & 34 \\
Andesine & 4 \\
Bytownite & Trace \\
Zeolite & Trace \\
Lithic Fragments & 8 \\
\hline
\end{tabular}

Sumber: Fiantis et al., 2009

Tabel 4. Komposisi Mineral Primer Material Piroklastik Erupsi Tahun 2010

\begin{tabular}{lc}
\hline Tipe Mineral & Kandungan (\%) \\
\hline Plagioklas & 57 \\
Piroksen & 37 \\
Opak & 6 \\
\hline
\end{tabular}

Sumber: Hasil analisis material vulkanik Merapi menggunakan mikroskop polarisasi, 2015

Dari Tabel 3 dan Tabel 4, terlihat bahwa material piroklastik yang dikeluarkan oleh erupsi tahun 2006 berbeda dari erupsi tahun 2010. Hasil erupsi tahun 2006 didominasi oleh tipe mineral volcanic glass (60\%) dan labradorite (34\%). Sementara pada tahun 2010 didominasi oleh plagioklas (57\%) dan piroksen (37\%), sisanya berupa tipe mineral opak (6\%). Mineral yang masuk ke dalam kelompok plagioklas dan piroksen tergolong mineral yang mudah lapuk (weathereable mineral), sehingga akan mengalami pelapukan pada fase paling awal. Tidak ditemukannya volcanic glass pada material tersebut diduga proses intrusi magma yang terjadi sangat dangkal atau merupakan bagian inti dari tubuh lava. Apabila dilihat dari kandungan mineralnya, maka sifat magmanya termasuk pada andesit basaltik atau magma intermediet. Rose et al. (1979) cit. Ismangil (2009) menyatakan proses pengkristalan mineral dimulai dari olivin $+\mathrm{Ca}$ plagioklas; augit + Ca-Na plagioklas; hornblende $+\mathrm{Na}-\mathrm{Ca}$ plagioklas; biotit + Na-plagioklas; Kfeldspar; muscovite, dan kuarsa. Tahapan proses pengkristalan tersebut menunjukkan tahapan pelapukan mineral yang dapat terjadi dan juga stabilitas mineral. Semakin akhir pengkristalan mineral yang terjadi, maka semakin stabil juga mineral yang terbentuk.

Hasil analisis mineral menggunakan X-Ray terhadap sampel tanah dari ketiga titik adalah sebagai berikut: 

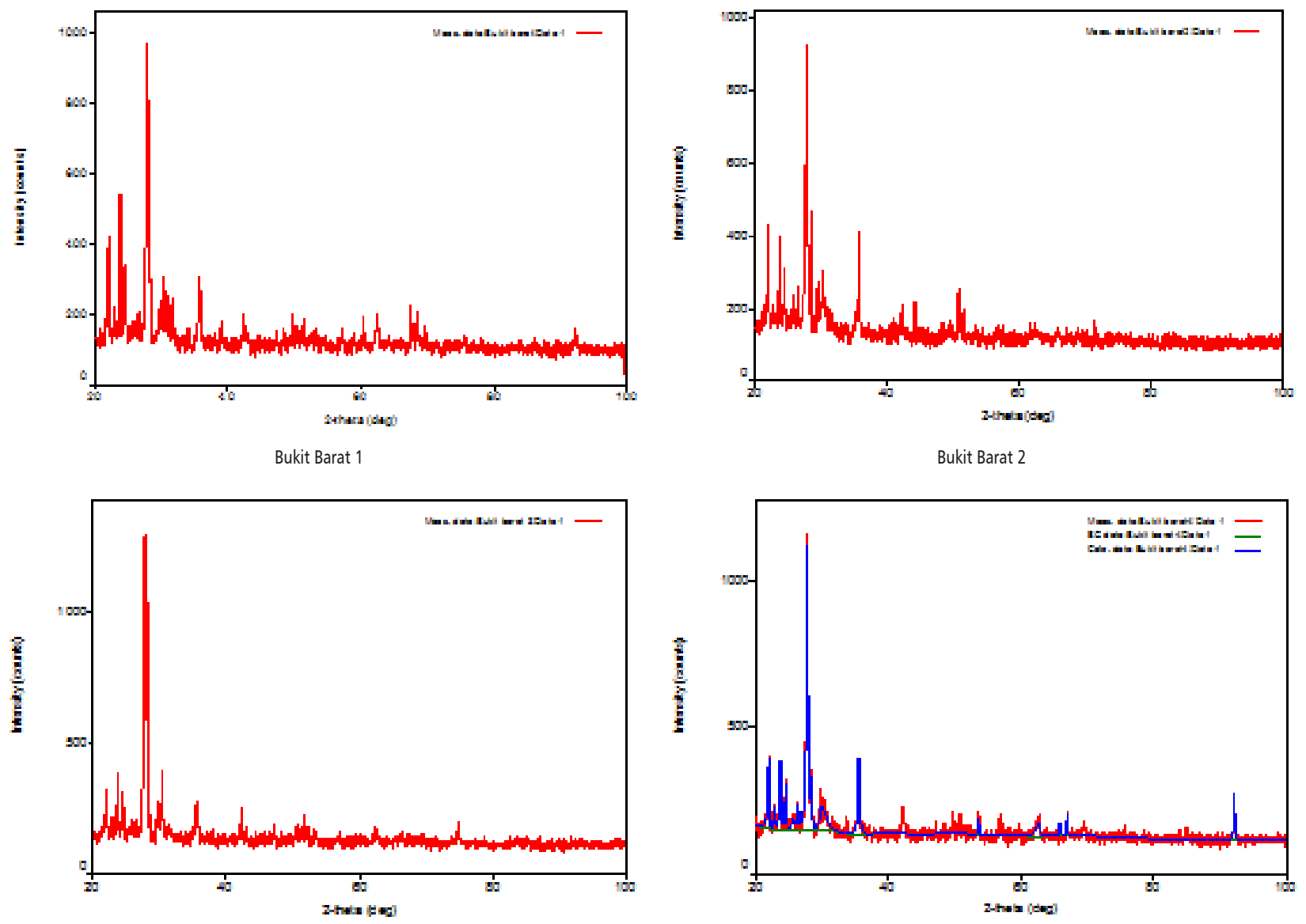

Bukit Barat 3
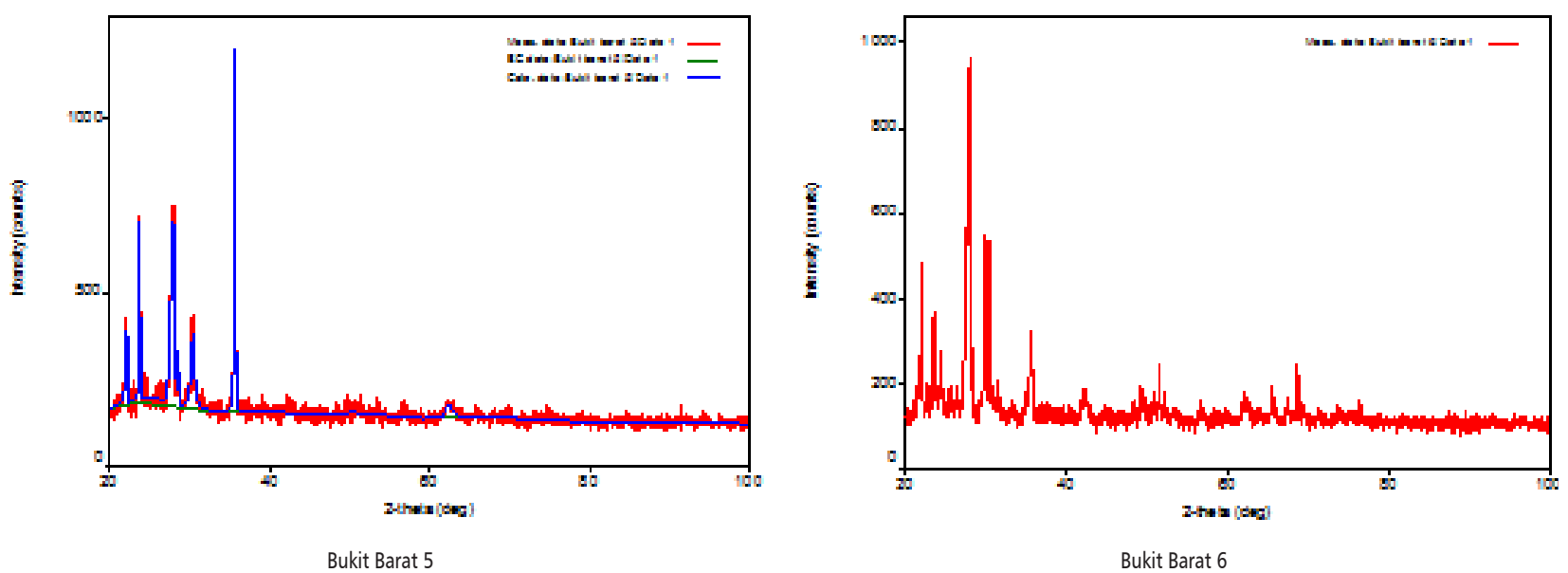

Gambar 2. Hasil X-RD Sampel Tanah Bukit Barat 


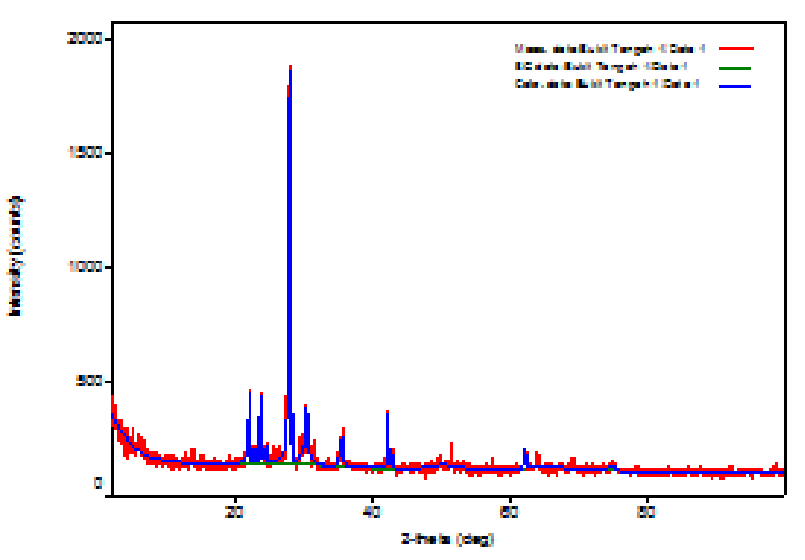

Bukit Tengah 1



Bukit Tengah 3

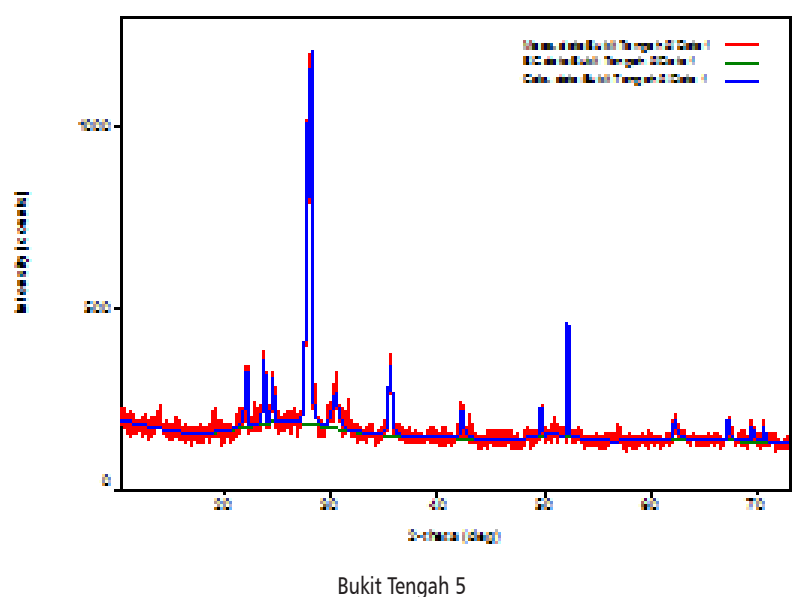

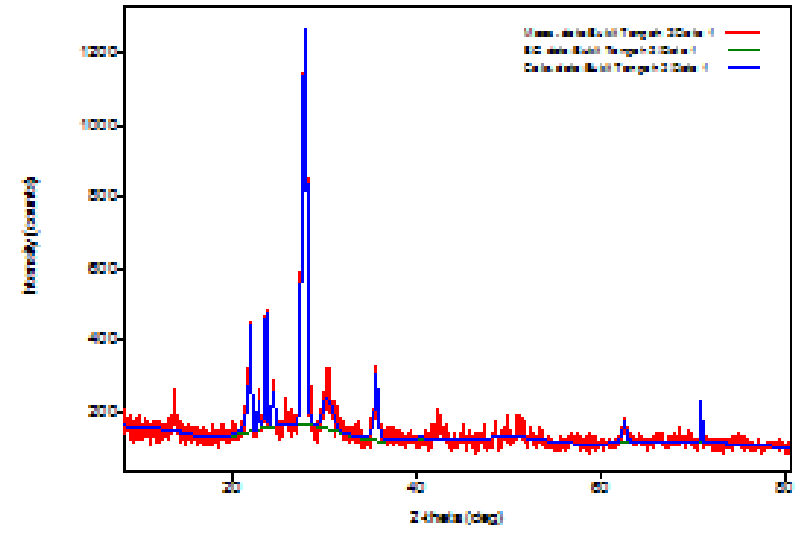

Bukit Tengah 2

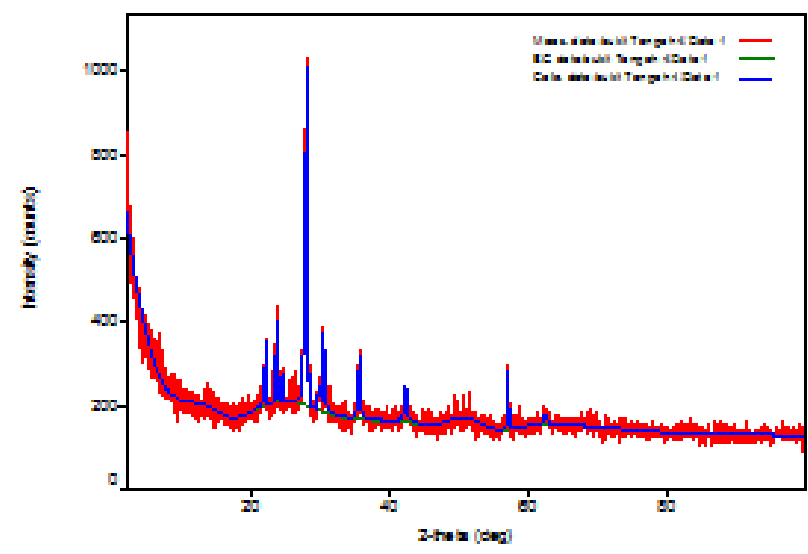

Bukit Tengah 4

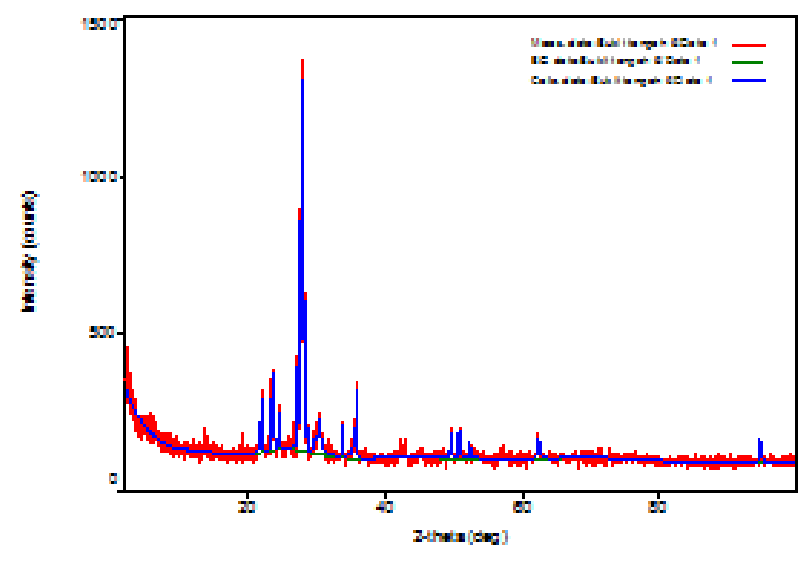

Bukit Tengah 6

Gambar 3. Hasil X-RD Sampel Tanah Bukit Tengah 

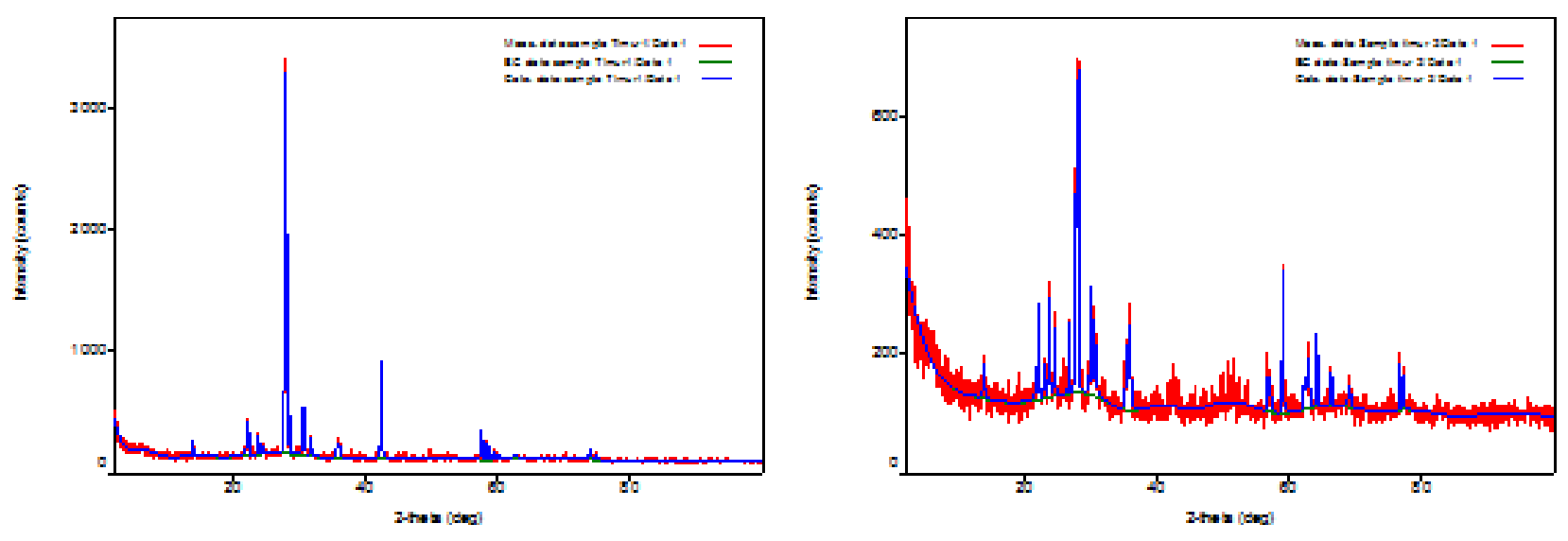

Bukit Timur 1

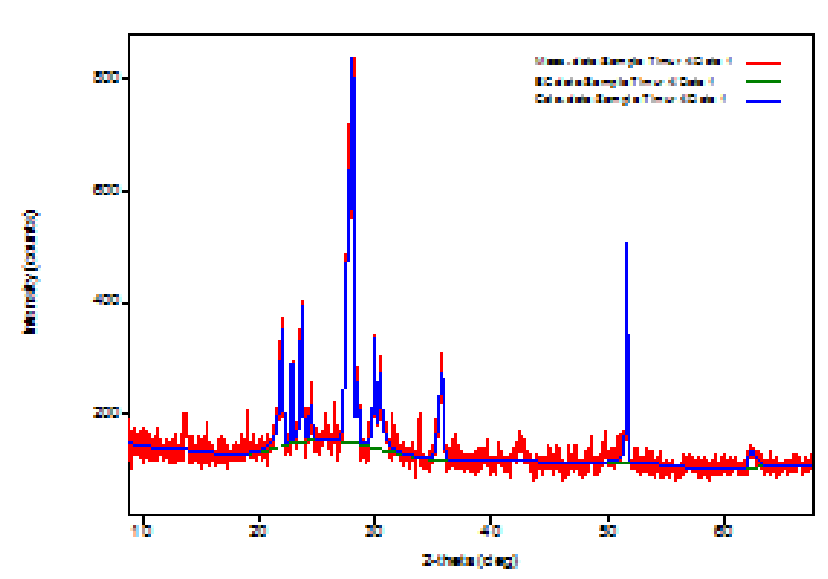

Bukit Timur 3

Bukit Timur 4

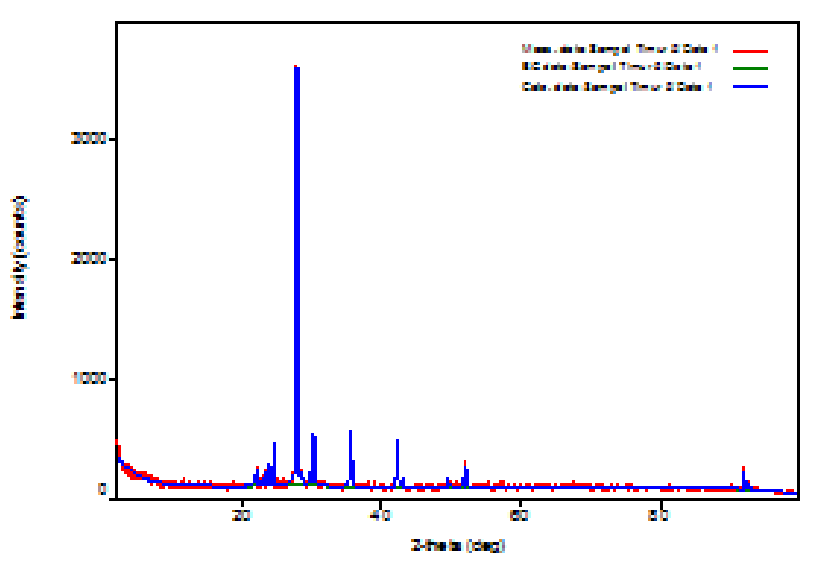

Bukit Timur 5

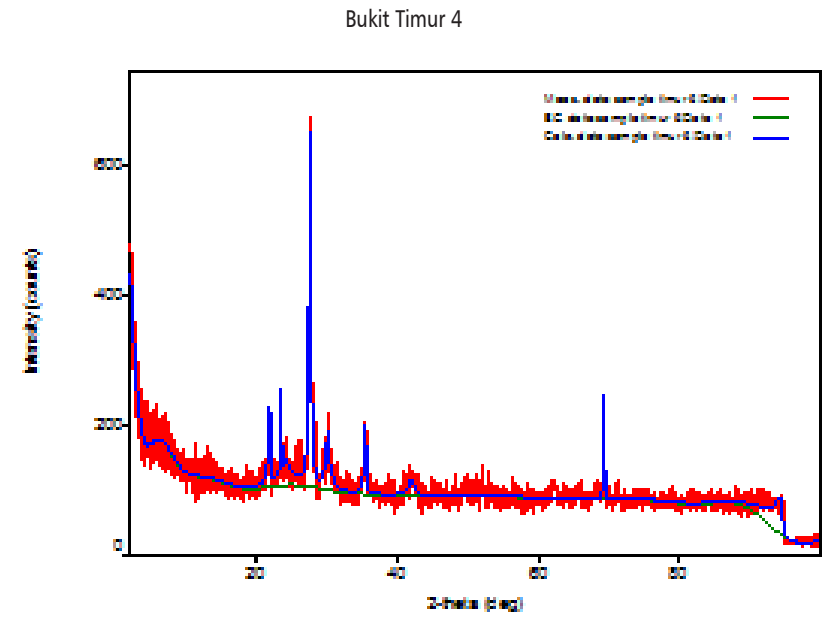

Bukit Timur 6

Gambar 4. Hasil X-RD Sampel Tanah Bukit Timur 


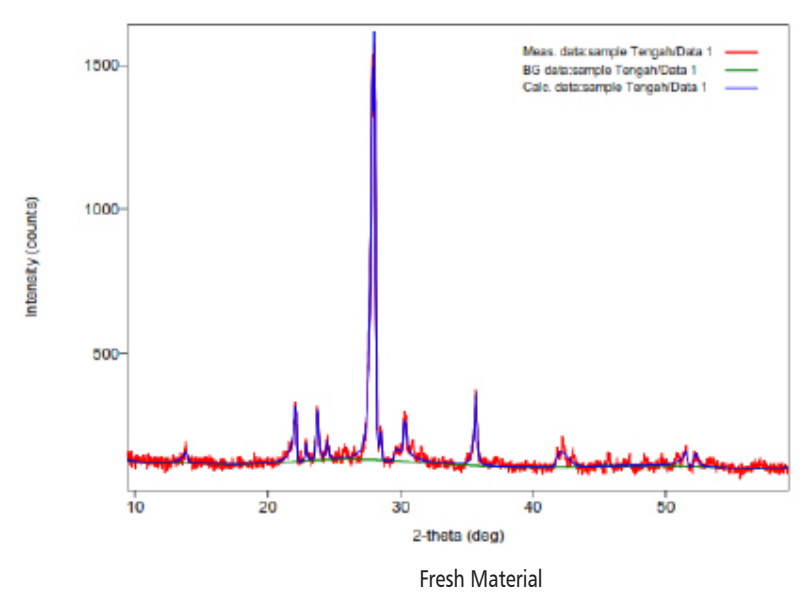

Gambar 5. Hasil X-RD Sampel Fresh Material

Tabel 5. Hasil Analisis Mineral Primer Mudah Lapuk Menggunakan X-Ray Diffraction

\begin{tabular}{|c|c|c|c|}
\hline No. & Titik Sampel & Mineral & Formula \\
\hline 1. & Bukit Barat 1 & Anorthite & $\mathrm{Ca}\left(\mathrm{Al}_{2} \mathrm{Si}_{2} \mathrm{O}_{8}\right)$ \\
\hline 2. & Bukit Barat 2 & Albite & $\mathrm{Na}\left(\mathrm{AlSi}_{3} \mathrm{O}_{8}\right)$ \\
\hline 3. & Bukit Barat 3 & Anorthite & $\mathrm{Ca}\left(\mathrm{Al}_{2} \mathrm{Si}_{2} \mathrm{O}_{8}\right)$ \\
\hline 4. & Bukit Barat 4 & Anorthite & $\mathrm{Ca}\left(\mathrm{Al}_{2} \mathrm{Si}_{2} \mathrm{O}_{8}\right)$ \\
\hline 5. & Bukit Barat 5 & Albite & $\mathrm{Na}\left(\mathrm{AlSi}_{3} \mathrm{O}_{8}\right)$ \\
\hline 6. & Bukit Barat 6 & Albite & $\mathrm{Na}\left(\mathrm{AlSi}_{3} \mathrm{O}_{8}\right)$ \\
\hline 7. & Bukit Tengah 1 & Anorthite & $\mathrm{Ca}\left(\mathrm{Al}_{2} \mathrm{Si}_{2} \mathrm{O}_{8}\right)$ \\
\hline 8. & Bukit Tengah 2 & Albite & $\mathrm{Na}\left(\mathrm{AlSi}_{3} \mathrm{O}_{8}\right)$ \\
\hline 9. & Bukit Tengah 3 & Anorthite & $\mathrm{Ca}\left(\mathrm{Al}_{2} \mathrm{Si}_{2} \mathrm{O}_{8}\right)$ \\
\hline 10. & Bukit Tengah 4 & Anorthite & $\mathrm{Ca}\left(\mathrm{Al}_{2} \mathrm{Si}_{2} \mathrm{O}_{8}\right)$ \\
\hline 11. & Bukit Tengah 5 & Anorthite & $\mathrm{Ca}\left(\mathrm{Al}_{2} \mathrm{Si}_{2} \mathrm{O}_{8}\right)$ \\
\hline 12. & Bukit Tengah 6 & Anorthite & $\mathrm{Ca}\left(\mathrm{Al}_{2} \mathrm{Si}_{2} \mathrm{O}_{8}\right)$ \\
\hline 13. & Bukit Timur 1 & Anorthite & $\mathrm{Ca}\left(\mathrm{Al}_{2} \mathrm{Si}_{2} \mathrm{O}_{8}\right)$ \\
\hline 14. & Bukit Timur 2 & Anorthite & $\mathrm{Ca}\left(\mathrm{Al}_{2} \mathrm{Si}_{2} \mathrm{O}_{8}\right)$ \\
\hline 15. & Bukit Timur 3 & Anorthite & $\mathrm{Ca}\left(\mathrm{Al}_{2} \mathrm{Si}_{2} \mathrm{O}_{8}\right)$ \\
\hline 16. & Bukit Timur 4 & Anorthite & $\mathrm{Ca}\left(\mathrm{Al}_{2} \mathrm{Si}_{2} \mathrm{O}_{8}\right)$ \\
\hline 17. & Bukit Timur 5 & Anorthite & $\mathrm{Ca}\left(\mathrm{Al}_{2} \mathrm{Si}_{2} \mathrm{O}_{8}\right)$ \\
\hline 18. & Bukit Timur 6 & Anorthite & $\mathrm{Ca}\left(\mathrm{Al}_{2} \mathrm{Si}_{2} \mathrm{O}_{8}\right)$ \\
\hline 19. & Fresh Material & Anorthite & $\mathrm{Ca}\left(\mathrm{Al}_{2} \mathrm{Si}_{2} \mathrm{O}_{8}\right)$ \\
\hline
\end{tabular}

Berdasar hasil analisis menggunakan X-Ray Diffraction (X-RD), dari semua sampel yang diambil menunjukkan bahwa tanah yang terbentuk dari bahan induk material vulkanik Merapi mengandung mineral primer mudah lapuk albite atau anorthite. Kedua mineral tersebut merupakan bagian dari mineral kelompok plagioklas. Hal ini sesuai dengan hasil analisis secara petrografi yang menunjukkan bahwa kandungan material erupsi Merapi adalah plagioklas (Tabel 4).

Apabila dilihat dari kandungan unsur mineral albite maupun anorthite, keduanya mempunyai kandungan unsur hara yang dibutuhkan oleh tanaman. Mineral primer anorthite mempunyai kandungan unsur hara dominan berupa $\mathrm{Ca}$, yang merupakan unsur hara makro bagi pertumbuhan tanaman. Sementara mineral primer albite mempunyai kandungan unsur hara dominan berupa $\mathrm{Na}$, yang merupakan unsur hara berguna bagi tanaman. Mineral primer albite merupakan mineral yang mengalami pelapukan lebih lanjut dibandingkan anorthite. Mineral ini terbentuk setelah sebagian kandungan unsur hara yang ada pada golongan Plagioklas berikatan membentuk mineral yang lain (Gambar 1).

Material abu vulkan yang dikeluarkan dari proses erupsi diyakini memiliki nilai keharaan yang sangat tinggi. Hal ini disebabkan oleh kandungan bermacam-macam unsur hara yang ada di dalamnya. Meskipun demikian unsur hara yang ada dalam mineral primer agar dapat diserap oleh tanaman, harus mengalami proses pelapukan atau dissolusi menjadi bentuk kation atau anion yang siap tersedia bagi tanaman (Kusumarini et.al, 2014). Kerusakan lahan pertanian yang tertimpa material abu volkan bersifat sementara, karena lahan tersebut akan mengalami rejuvinalisasi (pemudaan) kembali akibat suplai material segar yang kaya akan unsur hara makro $(\mathrm{Ca}, \mathrm{Mg}$, $\mathrm{K}, \mathrm{S})$, mikro (Zn, Fe, Cu, Mn) dan hara berguna (Si dan Na) (Hanudin, 2011).

Pemanfaatan mineral primer dalam batuan sebagai sumber hara tanaman sering diistilahkan dengan agrogeologi atau agromineral. Secara harfiah diartikan sebagai pemanfaatan sumberdaya geologi (mineral) sebagai sarana peningkatan produktivitas tanah (Van Starten, 1985 cit. Hanudin, 2011). Pemanfaatan tersebut dilaku- 
kan melalui penggunaan bahan-bahan geologi yang terbentuk secara alami, baik yang sudah diolah maupun belum diolah.

Banyak ahli telah mencoba menggunakan material volkanik untuk mereklamasi tanah-tanah marginal agar pertumbuhan tanaman menjadi lebih baik. Percobaan penggunaan abu volkanik untuk mereklamasi tanah gambut ombrogen dari Kalimantan mampu meningkatkan pertumbuhan dan serapan hara $\mathrm{Ca}, \mathrm{Mg}, \mathrm{K}, \mathrm{Cu}, \mathrm{Zn}, \mathrm{Mn}$, dan Fe tanaman jagung secara signifikan (Hanudin dan Utami, 2009; Hanudin et al., 2010). Penggunaan abu volkan untuk meningkatkan produktivitas kedelai juga dilakukan oleh Setiadi (1986) dimana pada takaran 12\% abu volkan yang diaplikasikan pada tanah gambut memberikan hasil yang paling baik. Bakken et al. (1997, 2000) menyatakan bahwa batuan beku yang mengandung K (sisa Feldspar) dapat memenuhi kebutuhan unsur $\mathrm{K}$ bagi tanaman rumput sebesar 30\%. Sementara pemanfaatan serbuk basal halus dan tufa basaltic mampu meningkatkan produksi kacang tanah pada tanah gampingan (Bakken et.al., 1997). Hasil penelitian Ismon (2006), pemanfaatan harsburgit dengan takaran 54 dan $432 \mathrm{~kg} \mathrm{MgO/ha} \mathrm{mampu} \mathrm{meningkatkan}$ bobot trubus kering dan serapan P pada tanaman jagung yang ditanam pada Typic Kandiudult.

Pemanfaatan unsur yang terkandung dalam mineral primer terjadi melalui proses pelarutan mineral. Pelarutan sendiri merupakan proses terbaginya suatu zat ke dalam zat lain, dalam bentuk zat padat dan air (Ismangil dan Hanudin, 2005). Kation-kation yang terlepas akan berada dalam larutan tanah atau juga terjerap pada permukaan partikel koloid. Sebagai contoh, reaksi pelarutan mineral K-Feldspar dalam tanah adalah sebagai berikut:

$\mathrm{KAlSi}_{3} \mathrm{O}_{8}+4 \mathrm{H}^{+}+4 \mathrm{H}_{2} \mathrm{O} \longleftrightarrow \mathrm{K}^{+}+\mathrm{Al}^{3+}+3 \mathrm{H}_{4} \mathrm{SiO}_{4}{ }^{0}$
Pelarutan mineral juga dapat terjadi karena adanya reaksi mineral dengan asam organik. Keberadaan asam-asam organik dapat mempercepat terjadinya pelarutan melalui interaksi dengan logam yang dilepaskan oleh reaksi pengasaman maupun logam yang berada pada permukaan kristal mineral (Ismangil dan Hanudin, 2005). Sebagai contoh, reaksi yang terjadi antara asam oksalat dengan muskovit berikut:

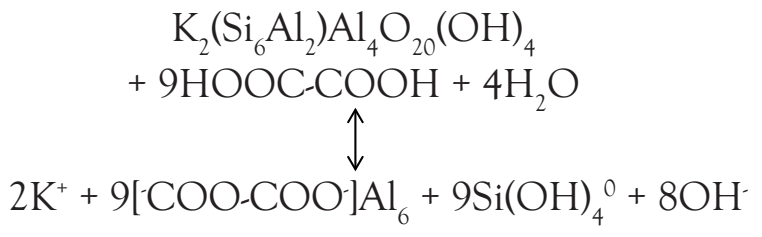

Reaksi di atas menggambarkan bahwa pelarutan sangat dipengaruhi oleh keberadaan ion $\mathrm{H}$, sehingga sebuah proses yang dapat menyebabkan perubahan konsentrasi ion $\mathrm{H}$ dapat menyebabkan perubahan kecepatan pelarutan mineral. Hal tersebut akan mempengaruhi kecepatan suatu unsur dalam mineral dapat tersedia bagi tanaman.

\section{SIMPULAN}

Material piroklastik Merapi berasal dari magma andesit basaltik dengan kandungan mineral primer mudah lapuk dominan berupa plagioklas (albite dan anorthite). Pemanfaatan material vulkanik sebagai agromineral dapat dilakukan, karena kandungan hara potensial yang ada dalam mineralnya, dan termasuk ke dalam golongan mineral yang mudah lapuk.

\section{UCAPAN TERIMAKASIH}

Ucapan terimakasih peneliti sampaikan kepada Dirjen DIKTI yang telah membiayai penelitian ini melalui dana penelitian Hibah Bersaing tahun 2015. 


\section{DAFTAR PUSTAKA}

Badan Geologi Kementerian Sumberdaya Energi dan Mineral. 2014. Karakteristik Gunung Merapi. http://merapi. bgl.esdm.go.id/informasi_merapi.php?page= informasimerapi\&subpage=karakteristik. Akses tanggal 13 Desember 2014.

Bakken, A.K., H. Gautneb and K. Myhr. 1997. The Potential of Crushed Rock and Mine Tailing as Slow-releasing K Fertilizer Assessed by Intensive Cropping of Italian Rygrass in Different Soil Type. Nutr. Cycl. Agroecosyst. 47:41-48.

Bakken, A.K., H. Gautneb, T. Sveistrup and K. Myhr. 2000. Crushed Rock and Mine Tailing Applied as K Fertilizers on Grassland. Nutr.Cycl.Agroecosystem 56:53-57.

Budi-Santoso, A., Philippe L., Sapari, D., Sri S.,Phillippe J., JeanPhilippe, M. 2013. Analysis of The Seismic Activity Associated with The 2010 Eruption of Merapi Volcano, Java. Journal of Volcano and Geothermal Research 261 : 153-170.

Fiantis, D., M. Nelson, Van Ranst, E., J. Shamshuddin, and N.P. Qafoku, 2009. Chemical Weathering of New Piroclastic Deposit from Mt. Merapi (Java), Indonesia. J.Mt.Sci. (2009) 6: 240-254.

Goldschmidt, V.M., 1958. Geochemistry. Oxford University Press. $730 p$.

Hanudin, E and S.N.H. Utami. 2009. Absorption of Ca, K, Mg and $\mathrm{Na}$ in Corn on The ombregenous Peat as Affected by Volcanic Ash and Flying Ash. Proceeding of Bogor Symposium and Workshop on Tropical Peat Management. 14-15 July 2009. Bogor Indonesia.

Hanudin, E. 2011. Pendekatan Agrogeologi Dalam Pemulihan Lahan Pertanian Pasca Erupsi Merapi (Agrogeology Approach In Recovering Agricultural Land After Merapi Volcano Eruption). Prosiding Seminar Nasional HITI. Universitas Sebelas Maret Surakarta, 26-27 April 2011.

Hanudin, E., Darmawan, B. Radjagukguk, S.N.H. Utami. 2010. Absorption and Distribution of Some Inicronutrients in Corn on The Ombrogenous Peat as Affected by Volcanic Ash and Flying Ash Application. Proceeding of Palangka Raya International Symposium \& Workshop On Tropical Peatland "The Proper Use of Tropical Peatland" 9-11 JUNE 2010. Palangkaraya. Indonesia.

Ismangil dan E. Hanudin. 2005. Degradasi Mineral Batuan oleh Asam-asam Organik. Jurnal IImu Tanah dan Lingkungan Vol. 5(1): 1-17.

Ismangil, 2009. Potensi Batu Beku, Kalsit, dan Campurannya Sebagai Amelioran Pada Bahan Tanah Lempung Aktivitas Rendah. Disertasi. Program Pascasarjana Universitas Gadjah Mada Yogyakarta. 395hal.

Ismon, L. 2006. Pengaruh Harsburgit (Batu Ultrabasis) dan Kiserit terhadap Ketersediaan Mg dan P serta Pertumbuhan Jagung pada Typic Kandiudult. Jurnal Tanah Tropika, Vol. 11, No. 2:71-79.

Ivanov, A, S. Shoba and P. Krasilnikov. 2014. A Pedogeographical View of Volcanic Soils Under Cold Humid Conditions: The Commander Islands. Geoderma 235-236 (2014): 48-58.

Jessey, D. and D. Tarman. 2014. Mineral Identification: The Beauty of Nature. http://geology.csupomona.edu/mineral/ minerals.htm. Akses 14 Desember 2014.
Kusumarini, N, S.R. Utami dan Z. Kusuma, 2014. Pelepasan Kation Basa Pada Bahan Piroklastik Gunung Api. Jurnal Tanah dan Sumberdaya Lahan. Vol 1 No 2:1-8.

Mason, B. and Carleton, B.M., 1982. Principles of Geochemistry. $4^{\text {th }}$ ed. John Wiley \& Sons. New York.

Mitchell, J.K. and K. Soga, 2005. Fundamental of Soil Behavior. $3^{\text {rd }}$ ed. John Wiley \& Sons, Inc. United States of America. 558p.

[PVMBG] Pusat Vulkanologi dan Mitigasi Bencana Geologi, 2006. Laporan dan Kajian Vulkanisme Erupsi: Edisi Khusus Erupsi Merapi 2006. Pusat Vulkanologi dan Mitigasi Bencana Geologi. Balai Penyelidikan dan Pengembangan Teknologi Kegunungapian. Yogyakarta. 292p.

Setiadi, B. 1996. Kajian Penggunaan Amelioran terhadap Serapan Hara, Pertumbuhan dan Hasil Kedelai pada Tanah Gambut. Disertasi. Program Pascasarjana Universitas Gadjah Mada Yogyakarta.205hal.

[USGS] United State Geological Survey, 2014. Volcano Hazards Program: Volcanic Rock. U.S. Geological Survey. http://volcanoes.usgs.gov/images/pglossary/ VolRocks.php. Akses 2 September 2014. 